\title{
Complete sequence of the mitochondrial genome of the Japanese buff-tip moth, Phalera flavescens (Lepidoptera: Notodontidae)
}

\author{
Q.-Q. Sun ${ }^{1}$, X.-Y. Sun ${ }^{2}$, X.-C. Wang ${ }^{1}$, Y.-H. Gai ${ }^{2}$, J. Hu ${ }^{1}$, C.-D. Zhu ${ }^{3}$ and \\ J.-S. Hao ${ }^{1}$ \\ ${ }^{1}$ Laboratory of Molecular Evolution and Biodiversity, \\ College of Life Sciences, Anhui Normal University, Wuhu, P.R. China \\ ${ }^{2}$ Key Laboratory of Palaeobiology and Stratigraphy, \\ Nanjing Institute of Geology and Palaeontology, \\ Chinese Academy of Sciences, Nanjing, P.R. China \\ ${ }^{3}$ Key Laboratory of Zoological Evolution and Systematics, \\ Institute of Zoology, Chinese Academy of Sciences, Beijing, P.R. China \\ Corresponding author: J.-S. Hao \\ E-mail: jshaonigpas@sina.com
}

Genet. Mol. Res. 11 (4): 4213-4225 (2012)

Received November 23, 2011

Accepted June 30, 2012

Published September 10, 2012

DOI http://dx.doi.org/10.4238/2012.September.10.2

\begin{abstract}
We sequenced the complete mitochondrial genome of Phalera flavescens. The mitogenome is $15,659 \mathrm{bp}$ in length, including 13 protein-coding genes (atp6, atp8, cox1-3, nad1-6, nad4L, cob), two ribosomal RNAs ( $r r n S$ and $r r n L), 22$ transfer RNAs and an AT-rich region, a putative control region (D-loop). Gene order and orientation were found to be identical to those of other completely sequenced lepidopteran mitogenomes. All 13 protein-coding genes start with the common codon ATN, except for the coxl gene, which uses CGA as the initial codon. Nine of the 13 protein-coding genes stop with codon TAA, while the cox1, cox2, nad5, and nad4 genes stop with the single nucleotide T. All tRNA genes can be folded into canonical cloverleaf secondary structure, except for trnSl, which loses the "DHU" arm. Six overlapping sequences totaling $20 \mathrm{bp}$ (1-8 bp for each sequence)
\end{abstract}


and 16 intergenic spacer sequences, totaling $276 \mathrm{bp}$ (1-58 bp for each sequence) are scattered throughout the genome; the largest intergenic spacer is located between the $\operatorname{trn} Q$ and $n a d 2$ genes. A microsatellitelike structure $(\mathrm{AT})_{6} \mathrm{ACC}(\mathrm{AT})_{6}$ and $16-\mathrm{bp}$ poly-T elements preceded by the ATTTA motif are present in the D-loop region. Additionally, unexpectedly, an extra 190-bp insertion, with unknown function, was found in the small subunit rRNA gene $(r r n S)$; this gene is the longest known (1020 bp) among all of the Lepidoptera.

Key words: Notodontidae; Phalera flavescens; Mitochondrial genome; rrnS; 190-bp insertion

\section{INTRODUCTION}

Mitochondrial genome (mtDNA) is a small molecule of $15-20 \mathrm{~kb}$ in length in most metazoans, which plays an important role in the process of metabolism, programmed cell death, illness, aging, etc. It is generally circular with a remarkably conserved set of 37 genes: 13 protein-coding genes (PCGs) (nadl-6 and nad4L for NADH dehydrogenase subunits 1-6, and 4L; atp 6 and atp 8 for ATPase subunits 6 and 8; cox $1-3$ for cytochrome oxidase subunits IIII; cob for cytochrome b), $r r n S$ and $r r n L$ for $12 \mathrm{~S}$ rRNA and $16 \mathrm{~S}$ rRNA, and 22 tRNAs (Boore, 1999). In addition, it usually contains at least one variable sequence about $1 \mathrm{~kb}$ in size, known as the AT-rich region (D-loop) (Zhang et al., 1995; Zhang and Hewitt, 1997). During the last few decades, mitochondrial genome sequence data, especially those of PCGs have been employed as a powerful tool for phylogenetics and evolutionary studies.

The order Lepidoptera is one of the largest insect orders, including more than 160,000 described species. Despite this huge species diversity, to date, only about $27 \mathrm{mtDNAs}$ have been fully sequenced, among which only one is of the Notodontidae (Salvato et al., 2008).

The Japanese buff-tip moth Phalera flavescens is a member of the family Notodontidae and an important species of insect pests, which is harmful to many economic plants, such as Malus pumila, Pyrus bretschneideri, Amygdalus persica, Prunus salicina, and others. This commonly found species is distributed throughout all areas of China and some areas of Japan and Korea. In this study, the complete mitochondrial genome sequence of $P$. flavescens was determined through PCR and primer-walking methods, and described in comparison with that of other sequenced lepidopterans in terms of genome organization, the characteristics of individual tRNAs, rRNAs, PCGs, and the non-coding regions, including the AT-rich region. Thus, the newly sequenced $P$. flavescens mitogenome is very useful to enrich our knowledge about lepidopteran mitogenomes and to supply more information for the studies of relevant areas.

\section{MATERIAL AND METHODS}

\section{Specimen collection}

The adult specimen of $P$. flavescens (Lepidoptera: Notodontidae) was obtained from Changping District of Beijing city, China, in August 2010. After the specimen collection, the material was placed in $100 \%$ ethanol immediately for preservation and fixation, brought to our laboratory and stored at $-20^{\circ} \mathrm{C}$ until use for genomic DNA extraction. 


\section{DNA extraction, primer design and PCR amplification}

Total genomic DNA of $P$. flavescens was extracted from thoracic muscle tissue of the adult specimen using the proteinase K-SOi ${ }_{2}$ method of Hao et al. (2005). Some partial short sequences of $\operatorname{cox} 1, \operatorname{cox} 2, \operatorname{nad} 5, \operatorname{cob}, \mathrm{nad} 4, \mathrm{rrnL}$, and $r r n S$ were amplified by the PCR protocol: denaturation for $5 \mathrm{~min}$ at $95^{\circ} \mathrm{C}$, followed by 35 cycles of denaturation for $50 \mathrm{~s}$ at $95^{\circ} \mathrm{C}$, annealing for $50 \mathrm{~s}$ at $55^{\circ} \mathrm{C}$, and elongation for $1 \mathrm{~min}$ at $72^{\circ} \mathrm{C}$, and a final extension step at $72^{\circ} \mathrm{C}$ for $10 \mathrm{~min}$. The PCR products were then sequenced using the primer set for the complete mitochondrial genomes of all the lepidopterans available or reported in Simon et al. (1994). The amplification of the six long fragments (rrnS-nad2, nad2-cox3, cox3-nad5, nad5-nad4, nad4-cob, cob-rrnS) (Table 1) were performed using TaKaRa LA Taq ${ }^{\mathrm{TM}}$ (Takara Bio, Japan) by the long PCR conditions: an initial denaturation for $5 \mathrm{~min}$ at $95^{\circ} \mathrm{C}$, followed by 15 cycles of denaturation for $50 \mathrm{~s}$ at $95^{\circ} \mathrm{C}$, annealing for $60 \mathrm{~s}$ at $48^{\circ}-58^{\circ} \mathrm{C}$, elongation for $150 \mathrm{~s}$ at $68^{\circ} \mathrm{C}$; then another 15 cycles of denaturation for $50 \mathrm{~s}$ at $95^{\circ} \mathrm{C}$, annealing for $60 \mathrm{~s}$ at $48^{\circ}-58^{\circ} \mathrm{C}$, and elongation for $150 \mathrm{~s}$ per cycle at $68^{\circ} \mathrm{C}$, and a final extension at $68^{\circ} \mathrm{C}$ for $10 \mathrm{~min}$. Two primers 5'-GAAACACTTTCCAGTACCT-3' and 5'-CTAAACCAATTCAACATCC-3' were designed for amplifying the $D$-loop region between the $r r n \mathrm{~S}$ and $n a d 2$ genes through the comparison of all lepidopteran mitochondrial genomes available.

\begin{tabular}{|c|c|c|}
\hline Primers & Upper primer sequence $\left(5^{\prime}-3^{\prime}\right)$ & Lower primer sequence (5'-3') \\
\hline nad2-cox3 & ССССТСТТТСТТСТААТА & TTGTATGTTTACCTTGGA \\
\hline cox3-nad5 & AAAGGATTACGATGAGGT & TCCAGTTAAGGGTCAAGGACTAT \\
\hline nad5-nad4 & TAAAAAAGGAATCCCACA & GCGTTTACATAGACGAAGA \\
\hline$n a d 4-c o b$ & CGTCTATGTAAACGCTCA & ATAAGGGTTTTCTACTGGT \\
\hline cob-rrnS & CGTGTTATTACTTTACTTG & AAACTAGGATTAGATACCC \\
\hline $\operatorname{rrnS}$-nad2 & GAAACACTTTCCAGTACCT & CTAAACCAATTCAACATCC \\
\hline
\end{tabular}

\section{Sequence analysis}

Raw sequence files were proofread and assembled in BioEdit version 7.0 (Hall, 1999). Sequences overlapping fragments were assembled by aligning neighboring fragments using the Clustal X1.83 software (Thompson et al., 1997). The 22 tRNA genes were identified by the tRNAscan-SE v.1.21 software (http://lowelab.ucsc.edu/tRNAscan-SE) (Lowe and Eddy, 1997). Nucleotide composition and codon usage were calculated using the MEGA4.0 software (Kumar et al., 2004). The base composition characteristics showing the relative number of A to $\mathrm{T}$ as AT skew (AT skew $=[\mathrm{A}-\mathrm{T}] /[\mathrm{A}+\mathrm{T}])$ and $\mathrm{G}$ to $\mathrm{C}$ as $\mathrm{GC}$ skew $(\mathrm{GC}$ skew $=[\mathrm{G}-\mathrm{C}] /$ $[\mathrm{G}+\mathrm{C}]$ ) were determined as proposed by Perna and Kocher (1995). Protein-coding genes and RNA genes were identified by sequence comparison with the published insect mitogenome sequences using SEQUIN (version 11.0). The mitogenome sequence data have been deposited in the GenBank database under the accession No. JF440342. The secondary structures of $r r n L$ and $r r n S$ were drawn using the XRNA software (http://rna.ucsc.edu/rnacenter/xrna/xrna.html).

\section{RESULTS AND DISCUSSION}

\section{Genome organization}

The $P$. flavescens mitochondrial genome was 15,659 bp in length (Figure 1 and Table 
$2)$; the size is well within the range of the other lepidopteran mitochondrial genomes from 15,140 bp in Artogeia melete (Hong et al., 2009) to 16,094 bp in Papilio maraho (Feng et al., 2010). It had the same gene content observed in typical metazoan mitogenomes [13 PCGs, two rRNA ( $r r n S$ and $r r n L), 22$ tRNA genes and a D-loop region]. The mitogenome had the same gene order and orientation as the completely sequenced lepidopteran mitogenomes (Kim et al., 2010), with its major strand coding for nine PCGs and 14 tRNAs, while the minor strand coding for four PCGs, eight tRNAs and two rRNAs. The overall base compositions of the mitogenome L-strand was $40.00 \% \mathrm{~A}, 40.82 \% \mathrm{~T}, 7.90 \% \mathrm{G}$, and $11.28 \% \mathrm{C}$, showing a relatively strong AT bias $(80.82 \%)$. This AT bias value is within the range from $77.9 \%$ in Ochrogaster lunifer to $82.7 \%$ in Coreana raphaelis (Kim et al., 2006; Salvato et al., 2008) as well. Additionally, the major strand AT skew was slightly negative (-0.01017), which is also within the range of the other lepidopterans, from -0.04748 in C. raphaelis (Kim et al., 2006) to 0.05872 in Bombyx mori (Yukuhiro et al., 2002).

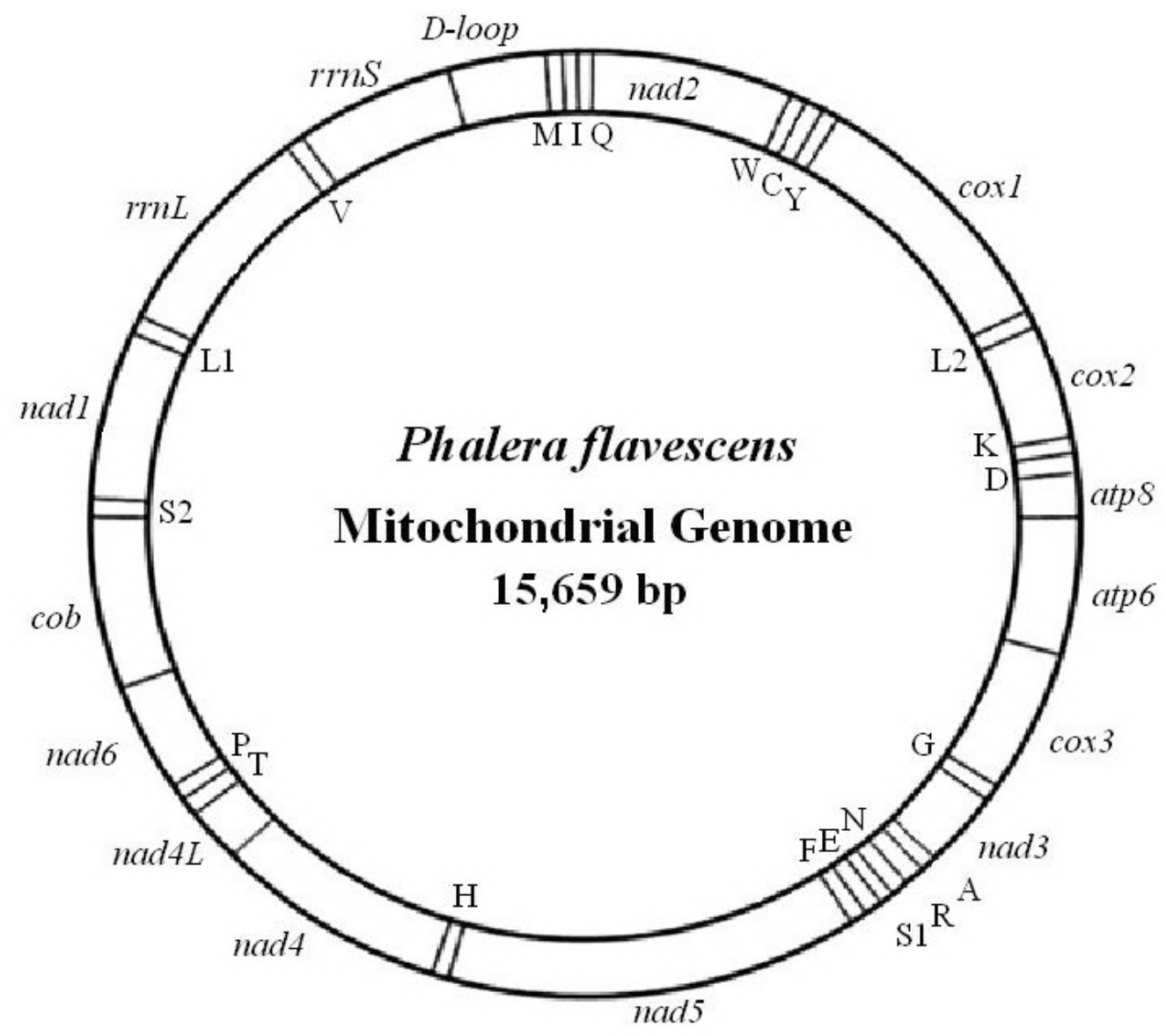

Figure 1. Map of the mitochondrial genome of Phalera flavescens. tRNAs are denoted as one-letter symbol according to the IUPAC-IUB single-letter amino acid codes. coxl-3 = cytochrome oxidase subunits; $c o b=$ cytochrome b; nad1-6 = NADH dehydrogenase components. 
Table 2. Summary of the Phalera flavescense mitogenome.

\begin{tabular}{|c|c|c|c|c|c|c|}
\hline Gene & Direction & Nucleotide No. & Size (bp) & Intergenic nucleotides & Start codon & Stop codon \\
\hline trnM & $\mathrm{F}$ & $1-68$ & 68 & 0 & & \\
\hline $\operatorname{trnI}$ & $\mathrm{F}$ & $69-135$ & 67 & 0 & & \\
\hline $\operatorname{trn} Q$ & $\mathrm{R}$ & $133-201$ & 69 & -3 & & \\
\hline $\operatorname{nad2}$ & $\mathrm{F}$ & $260-1273$ & 1014 & 58 & ATT & TAA \\
\hline $\operatorname{trn} W$ & $\mathrm{~F}$ & $1289-1360$ & 72 & 15 & & \\
\hline $\operatorname{trn} C$ & $\mathrm{R}$ & $1353-1421$ & 69 & -8 & & \\
\hline $\operatorname{trn} Y$ & $\mathrm{R}$ & $1423-1488$ & 66 & 1 & & \\
\hline $\operatorname{cox} 1$ & $\mathrm{~F}$ & $1493-3024$ & 1532 & 5 & CGA & T-tRNA \\
\hline $\operatorname{trn} L 2$ & $\mathrm{~F}$ & $3025-3091$ & 67 & 0 & & \\
\hline $\cos 2$ & $\mathrm{~F}$ & $3092-3773$ & 682 & 0 & ATG & T-tRNA \\
\hline $\operatorname{trnK}$ & $\mathrm{F}$ & $3774-3844$ & 71 & 0 & & \\
\hline $\operatorname{trn} D$ & $\mathrm{~F}$ & $3863-3932$ & 70 & 18 & & \\
\hline atp 8 & $\mathrm{~F}$ & $3933-4091$ & 159 & 0 & ATT & TAA \\
\hline atp6 & $\mathrm{F}$ & $4088-4762$ & 675 & -4 & ATG & TAA \\
\hline $\operatorname{cox} 3$ & $\mathrm{~F}$ & $4762-5550$ & 789 & -1 & ATG & TAA \\
\hline $\operatorname{trn} G$ & $\mathrm{~F}$ & $5553-5618$ & 66 & 2 & & \\
\hline nad3 & $\mathrm{F}$ & $5616-5972$ & 357 & -3 & ATA & TAA \\
\hline $\operatorname{trn} A$ & $\mathrm{~F}$ & $5990-6054$ & 65 & 17 & & \\
\hline $\operatorname{trnR}$ & $\mathrm{F}$ & $6055-6119$ & 65 & 0 & & \\
\hline $\operatorname{trnN}$ & $\mathrm{F}$ & $6126-6191$ & 66 & 6 & & \\
\hline $\operatorname{trnS1}$ & $\mathrm{F}$ & $6199-6267$ & 69 & 7 & & \\
\hline $\operatorname{trn} E$ & $\mathrm{~F}$ & $6299-6367$ & 69 & 31 & & \\
\hline $\operatorname{trnF}$ & $\mathrm{R}$ & $6384-6450$ & 67 & 16 & & \\
\hline $\operatorname{nad} 5$ & $\mathrm{R}$ & $6451-8188$ & 1738 & 0 & ATT & T-tRNA \\
\hline $\operatorname{trnH}$ & $\mathrm{R}$ & $8189-8254$ & 66 & 0 & & \\
\hline nad4 & $\mathrm{R}$ & $8255-9632$ & 1378 & 0 & ATA & T-tRNA \\
\hline $\operatorname{nad} 4 L$ & $\mathrm{R}$ & $9656-9955$ & 300 & 23 & ATA & TAA \\
\hline $\operatorname{trn} T$ & $\mathrm{~F}$ & $9961-10026$ & 66 & 5 & & \\
\hline $\operatorname{trn} P$ & $\mathrm{R}$ & $10027-10091$ & 65 & 0 & & \\
\hline nad6 & $\mathrm{F}$ & $10097-10585$ & 489 & 5 & ATG & TAA \\
\hline$c o b$ & $\mathrm{~F}$ & $10586-11752$ & 1167 & 0 & ATT & TAA \\
\hline $\operatorname{trn} S 2$ & $\mathrm{~F}$ & $11752-11815$ & 64 & -1 & & \\
\hline nadl & $\mathrm{R}$ & $11846-12781$ & 936 & 30 & ATG & TAA \\
\hline trnL1 & $\mathrm{R}$ & $12783-12852$ & 70 & 1 & & \\
\hline$r r n L$ & $\mathrm{R}$ & $12853-14220$ & 1368 & 0 & & \\
\hline $\operatorname{trn} V$ & $\mathrm{R}$ & $14221-14288$ & 68 & 0 & & \\
\hline$r r n S$ & $\mathrm{R}$ & $14289-15308$ & 1020 & 0 & & \\
\hline D-loop & & $15309-15659$ & 351 & 0 & & \\
\hline
\end{tabular}

$\mathrm{F}=$ foward $\mathrm{R}=$ reverse.

\section{Protein-coding genes}

Like other lepidopterans, all 13 PCGs in the P. flavescens mitogenome had ATN as their start codon, except for coxl, and they typically showed TAG or TAA as stop codons, except for cox1, cox2, nad4, and nad5 (T-tRNA) (Table 2).

The start codon of the coxl gene has been widely discussed in the insect mtDNA (Yukuhiro et al., 2002). For example, some unusual oligonucleotides, such as the TTA in Panulirus japonicus (Yamauchi et al., 2002), TCG in Bactrocera oleae (Nardi et al., 2003), ACG in Vargula hilgendorfii (Ogoh and Ohmiya, 2004), TATCTA in Penaeis monodon (Wilson et al., 2000), TTTTAG in Bombyx mandarina (Yukuhiro et al., 2002), and TATTAG in Ostrinia nubilalis and $O$. furnicalis (Coates et al., 2005), have been proposed as the coxl start codons. As for the start codons for the lepidopteran coxl genes, they are also controversial. For example, some unusual start codons are also proposed for three butterfly species (A. melete, Parnassius bremeri and Eumenis autonue) and seven moth species (Antheraea pemyi, Adoxophyes honmai, Ochrogaster lunifer, Eriogyna pyretorum, B. mandarina, Lymantria dispar, 
and Manduca sexta) (Salvato et al., 2008; Kim et al., 2009; Kim et al., 2010). Owing to the fact that the CGA is present as a conserved region for all lepidopteran insects reported, we tend to consider that CGA is the start codon for P. flavescens coxl in this study as suggested by Kim et al. (2009).

The cox 2 gene harbored an incomplete stop codon of a single thymine with no canonical TAN stop codon detected in its terminating region. Such an incomplete stop codon is also detected in 29 other insect mitogenomes available (Cha et al., 2007; Hong et al., 2008; Kim et al., 2010) (Table 3). This single thymine as an incomplete codon detected in PCGs may be caused by posttranscriptional modifications during the mRNA maturation process, such as poly-adenylation. Summarizing, a total of 3727 non-stop codons are used in P. flavescens mitogenome PCGs, and this pattern is similar to that in other lepidopteran species as well.

\begin{tabular}{|c|c|c|c|}
\hline Species & Supperfamily/Family & GenBank accession No. & Reference \\
\hline Hyphantria cunea & Noctuoidea Arctiidae & $\mathrm{NC} 014058$ & Liao et al., 2010 \\
\hline Lymantria dispar & Lymantriidae & $\mathrm{NC}_{-}^{-} 012893$ & Zhu et al., 2010 \\
\hline Helicoverpa armigera & Noctuidae & $\mathrm{NC}_{-}^{-} 014668$ & Yin et al., 2010 \\
\hline Ochrogaster lunifer & Notodontidae & $\mathrm{NC}_{-} 011128$ & Salvato et al., 2008 \\
\hline Phalera flavescens & Notodontidae & JF440342 & This study \\
\hline Phthonandria atrilineata & Geometroidea Geometridae & NC_010522 & Yang et al., 2009 \\
\hline Spilonota lechriaspis & Tortricoidea Tortricidae & $\mathrm{NC}_{-}^{-} 014294$ & Zhao et al., 2011 \\
\hline Adoxophyes honmai & Tortricidae & $\mathrm{NC}^{-} 008141$ & Lee et al., 2006 \\
\hline Grapholitha molesta & Tortricidae & $\mathrm{NC}^{-} 014806$ & Gong et al., 2012 \\
\hline Antheraea pernyi & Bombycoidea Saturniidae & $\mathrm{NC}_{-}^{-} 004622$ & Liu et al., 2008 \\
\hline Antheraea yamamai & Saturniidae & $\mathrm{NC}_{-}^{-} 012739$ & Kim SR et al., 2009 \\
\hline Eriogyna pyretorum & Saturniidae & NC_-012727 & Jiang et al., 2009 \\
\hline Saturnia boisduvalii & Saturniidae & NC_010613 & Hong et al., 2008 \\
\hline Chinese Bombyx mandarina & Bombycidae & AY $\overline{3} 01620$ & Pan et al., 2008 \\
\hline Bombyx mandarina & Bombycidae & NC_ 003395 & Yukuhiro et al., 2002 \\
\hline Bombyx mori & Bombycidae & $\mathrm{NC}_{-}^{-} 002355$ & Yukuhiro et al., 2002 \\
\hline Manduca sexta & Sphingidae & $\mathrm{NC}_{-}^{-} 010266$ & Cameron and Whiting, 2008 \\
\hline Diatraea saccharalis & Pyraloidea Crambidae & $\mathrm{NC}^{-} 013274$ & Li et al., 2011 \\
\hline Ostrinia furnacalis & Crambidae & $\mathrm{NC}^{-} 003368$ & Coates et al., 2005 \\
\hline Ostrinia nubilalis & Crambidae & $\mathrm{NC}_{-}^{-} 003367$ & Coates et al., 2005 \\
\hline Eumenis autonoe & Papilionoidea Nymphalidae & $\mathrm{NC}^{-} 014587$ & Kim et al., 2010 \\
\hline Acraea issoria & Nymphalidae & GQ̄376195 & Hu et al., 2010 \\
\hline Sasakia charonda & Nymphalidae & NC_014224 & Hakozaki et al., unpublished results \\
\hline Sasakia charonda kuriyamaensis & Nymphalidae & $\mathrm{NC}^{-} 014223$ & Hakozaki et al., unpublished results \\
\hline Argyreus hyperbius & Nymphalidae & JF43 9070 & Wang et al., 2011 \\
\hline Papilio maraho & Papilionidae & NC_ 014055 & Feng et al., 2010 \\
\hline Parnassius bremeri & Papilionidae & NC_014053 & Kim et al., 2009 \\
\hline Teinopalpus aureus & Papilionidae & NC_014398 & Qin et al., 2012 \\
\hline Coreana raphaelis & Lycaenidae & NC_007976 & Kim et al., 2006 \\
\hline Artogeia melete & Pieridae & $\mathrm{NC}_{-}^{-} 010568$ & Hong et al., 2009 \\
\hline
\end{tabular}

${ }^{a}$ Hakozaki Y, Ueda J and Sato M.

The codon usage of PCGs of the P. flavescens mitochondrial genome is shown in Table 4. The results indicate that the codon usage of all the genes has a strong bias in that the relative synonymous codon usage values of NNU and NNA codons are essentially greater than the others, indicating a higher $\mathrm{U}+\mathrm{A}$ frequency of the third points compared to the others. The PCG codon usage bias and the third point of A+T bias (92.4\%) show a positive correlation. In addition, statistics also showed that UUU (Phe), UUA (Leu), AUU (Ile), AUA (Met), and AAU (Asn) are the most frequently used codons, accounting for $46.85 \%$ of all. 
Table 4. Codon usage of Phalera flavescens mitochondrial genome.

\begin{tabular}{|c|c|c|c|c|c|c|c|}
\hline \multirow{2}{*}{$\frac{\text { Codon(Aa) }}{\text { UUU(F) }}$} & \multicolumn{3}{|c|}{ Codon(Aa) } & \multirow{2}{*}{$\frac{\operatorname{Codon}(\mathrm{Aa})}{\mathrm{UAU}(\mathrm{Y})}$} & \multicolumn{3}{|c|}{ Codon(Aa) } \\
\hline & $338.0(1.86)$ & UCU(S) & $119.0(3.00)$ & & $177.0(1.90)$ & $\mathrm{UGU}(\mathrm{C})$ & $35.0(1.89)$ \\
\hline UUC(F) & $26.0(0.14)$ & $\mathrm{UCC}(\mathrm{S})$ & $15.0(0.38)$ & UAC(Y) & $9.0(0.10)$ & $\mathrm{UGC}(\mathrm{C})$ & $2.0(0.11)$ \\
\hline UUA(L) & $472.0(5.00)$ & UCA(S) & $64.0(1.62)$ & $\mathrm{UAA}(*)$ & $0.0(0.00)$ & UGA(W) & $89.0(1.84)$ \\
\hline UUG(L) & $18.0(0.19)$ & UCG(S) & $1.0(0.03)$ & UAG $(*)$ & $0.0(0.00)$ & UGG(W) & $8.0(0.16)$ \\
\hline CUU(L) & $44.0(0.47)$ & $\mathrm{CCU}(\mathrm{P})$ & $61.0(1.91)$ & CAU(H) & $51.0(1.59)$ & CGU(R) & $22.0(1.66)$ \\
\hline CUC(L) & $5.0(0.05)$ & $\mathrm{CCC}(\mathrm{P})$ & $16.0(0.50)$ & $\mathrm{CAC}(\mathrm{H})$ & $13.0(0.41)$ & CGC(R) & $1.0(0.08)$ \\
\hline CUA(L) & $26.0(0.28)$ & $\mathrm{CCA}(\mathrm{P})$ & $48.0(1.50)$ & CAA(Q) & $59.0(1.87)$ & CGA(R) & $30.0(2.26)$ \\
\hline CUG(L) & $1.0(0.01)$ & $\mathrm{CCG}(\mathrm{P})$ & $3.0(0.09)$ & CAG(Q) & $4.0(0.13)$ & CGG(R) & $0.0(0.00)$ \\
\hline AUU(I) & $435.0(1.92)$ & ACU(T) & $75.0(2.11)$ & AAU(N) & $245.0(1.90)$ & AGU(S) & $25.0(0.63)$ \\
\hline AUC(I) & $18.0(0.08)$ & $\mathrm{ACC}(\mathrm{T})$ & $12.0(0.34)$ & $\mathrm{AAC}(\mathrm{N})$ & $13.0(0.10)$ & $\mathrm{AGC}(\mathrm{S})$ & $2.0(0.05)$ \\
\hline AUA(M) & $256.0(1.87)$ & $\mathrm{ACA}(\mathrm{T})$ & $53.0(1.49)$ & $\mathrm{AAA}(\mathrm{K})$ & $104.0(1.89)$ & $\mathrm{AGA}(\mathrm{S})$ & $87.0(2.20)$ \\
\hline AUG(M) & $18.0(0.13)$ & $\mathrm{ACG}(\mathrm{T})$ & $2.0(0.06)$ & $\mathrm{AAG}(\mathrm{K})$ & $6.0(0.11)$ & AGG(S) & $4.0(0.10)$ \\
\hline GUU(V) & $66.0(1.82)$ & GCU(A) & $66.0(2.08)$ & GAU(D) & $58.0(1.73)$ & GGU(G) & $54.0(1.07)$ \\
\hline GUC(V) & $5.0(0.14)$ & GCC(A) & $10.0(0.31)$ & GAC(D) & $9.0(0.27)$ & GGC(G) & $2.0(0.04)$ \\
\hline GUA(V) & $70.0(1.93)$ & GCA(A) & $50.0(1.57)$ & GAA(E) & $67.0(1.81)$ & GGA(G) & $110.0(2.18)$ \\
\hline GUG(V) & $4.0(0.11)$ & GCG(A) & $1.0(0.03)$ & GAG(E) & $7.0(0.19)$ & GGG(G) & $36.0(0.71)$ \\
\hline
\end{tabular}

Data are reported as frequency of codon used with relative synonymous codon usage in parentheses. * Stop codon. Start codons and stop codons were excluded in total codons count of protein coding genes.

\section{Ribosomal and transfer RNA genes}

In the P. flavescens mitogenome, the $r r n L$ gene was located between sites 12,853 and 14,220 , for a total length of $1368 \mathrm{bp}$. Its reconstructed secondary structure (Figure 2) broadly conforms to that of M. sexta (Cameron and Whiting, 2008). The proposed secondary structure has 49 helices belonging to six domains. The stem regions of H1057/D18, H1087/D19 and H991/D17 in domain II are difficult to fold under the criteria of Watson-Crick pairs, and thus different from M. sexta with regard to a large internal loop. The stem H2347/G13 is also highly variable within the order Lepidoptera with regard to sequence variation and the (AT) insertion, such as (AT) ${ }_{14}$ in M. sexta and (AT) ${ }_{12}$ in Grapholitha molesta (Gong et al., 2012). While some bases indentified as highly conserved region, such as the stems H2064/G2, H2077/G3, H2246/G6, H2259/G7, H2282, and their correspondingly large loops are found adjacent to and even within the hypervariable region, these conserved sites may serve as anchor points for the secondary structure of the hypervariable region (Hao et al., 2007).

The $r r n S$ gene was located between positions 14,289 and 15,308, for a total $1020 \mathrm{bp}$ in length. Its secondary structure is basically the same as those of the other insect groups with 29 helices belonging to three domains (Niehuis et al., 2006) (Figure 3). However, compared to those of the 29 other lepidopteran species listed in Table 3, this gene was found to be the longest one, for example, a 190-bp extra-insertion was detected between the stem regions H505/20 and H515/21 by comparison with its closely related species $O$. lunifer (Figure 3 ). These insertion regions are shown to be highly variable among the currently available lepidopteran mtDNAs with their functions unknown. In addition, the stem H1047/38 is significantly variable among different lepidopteran species as well (Niehuis et al., 2006; Cameron and Whiting, 2008).

The $P$. flavescens mtDNA contained 22 tRNA genes, interspersed throughout the whole genome and ranging in size from 65 to $72 \mathrm{bp}$. All tRNAs except trnS1 folded into the expected secondary cloverleaf structures (Figure 4). The trnS1 lacked the DHU stem and this feature is common in the insect mitogenomes (Kim et al., 2006). In the 22 predicted tRNA secondary structures, 24 pairs of base mismatches were detected, and among which 17 were GU, 5 UU, 1 AG, and 1 UC (Figure 4). 


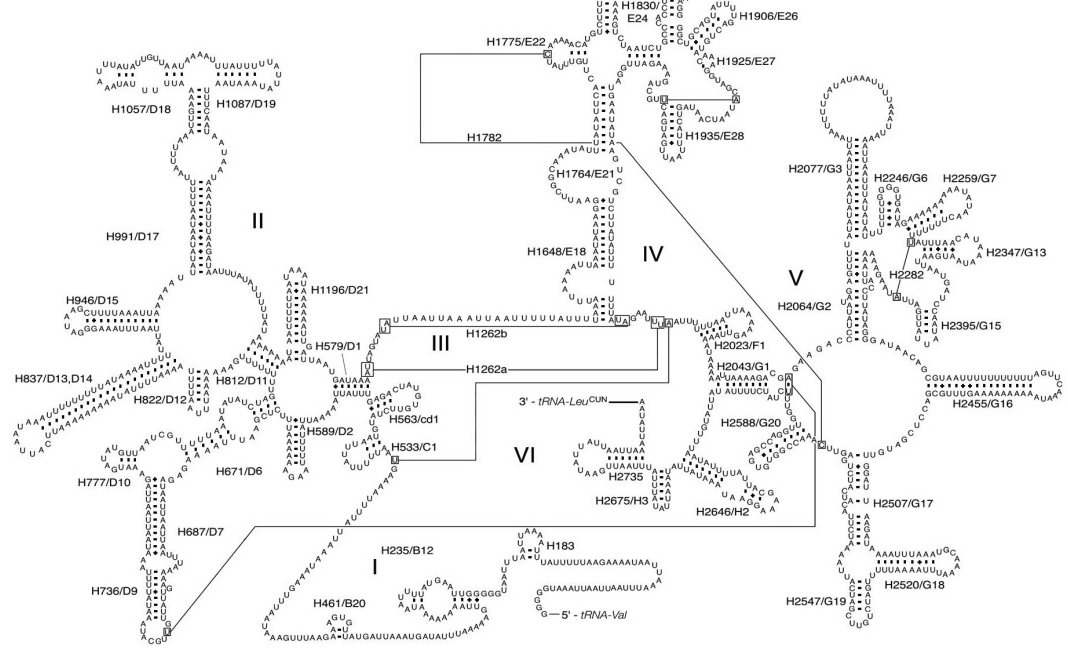

Figure 2. Secondary structure of the $r r n L$ of Phalera flavescens. Roman numberals denote the conserved domain structure. Helices are numbered according to Manaduca sexta. Tertiary structures are denoted by boxed bases joined by solid lines. Watson-Crick pairs are joined by dashes; non-canonical guanine-uracil and other non-canonical interactions are joined by plus signs.

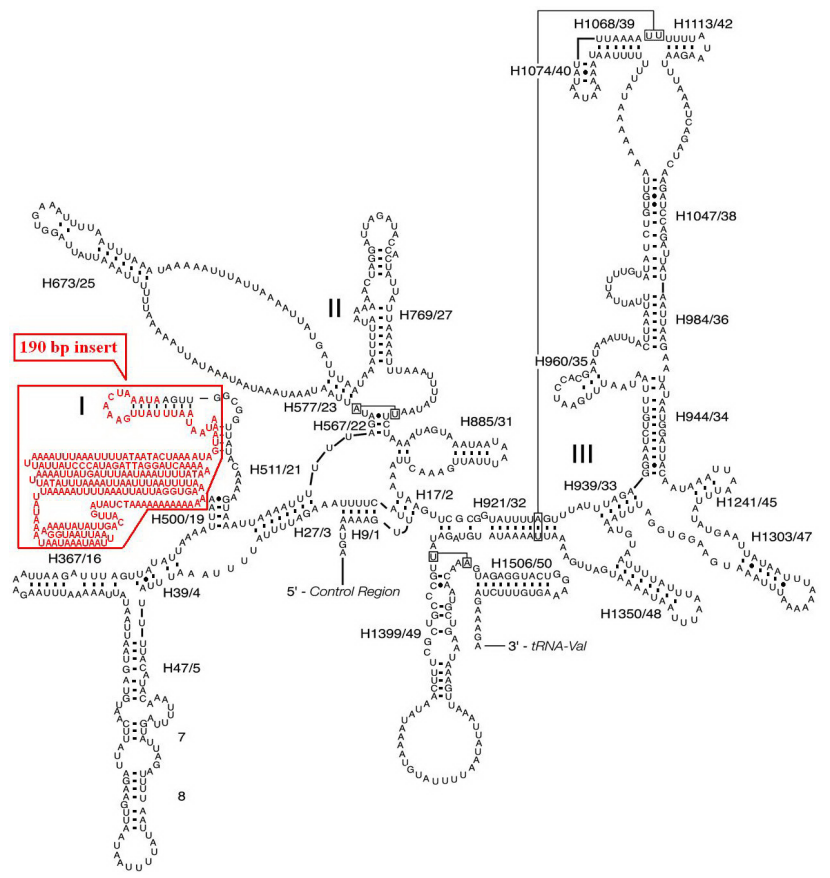

Figure 3. Secondary structure of the $r r n S$ of Phalera flavescens. Roman numberals denote the conserved domain structure. Helices are numbered according to Manaduca sexta. Tertiary structures are denoted by boxed bases joined by solid lines. Watson-Crick pairs and non-canonical guanine-uracil are joined by dashes; other non-canonical interactions are joined by a dot. The 190-bp insertions are marked in red color. 

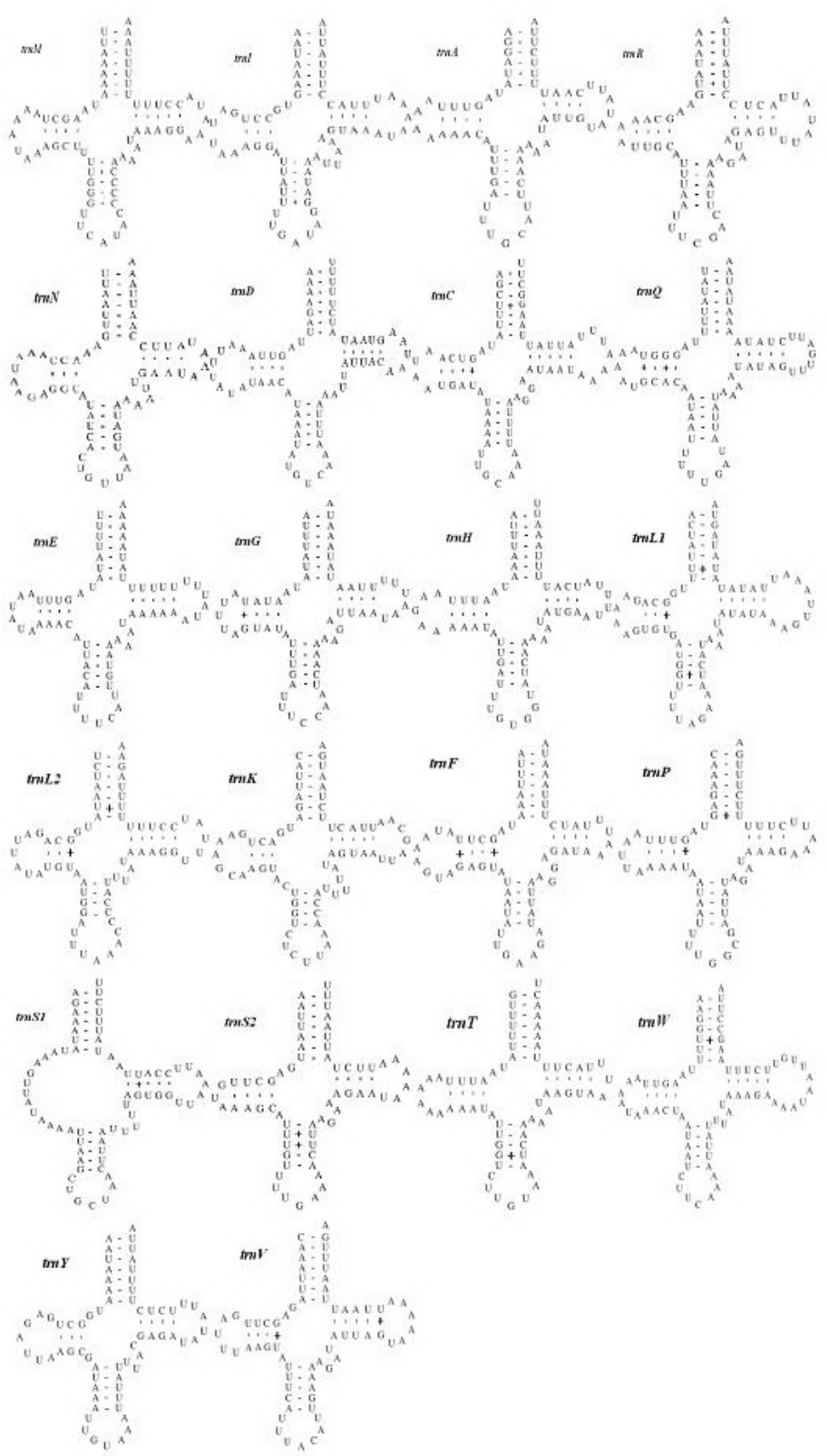

Figure 4. Secondary structures of the 22 tRNAs of the Phalera flavescens mitogenomes.

\section{Non-coding regions and overlapping sequences}

The non-coding regions included the AT-rich region (D-loop) and 16 intergenic spacer sequences. The intergenic spacers ranged from 1 to $58 \mathrm{bp}$ in size, totaling $276 \mathrm{bp}$ in length. 
The longest 58-bp spacers were present between the $\operatorname{trn} Q$ and $n a d 2$ genes. The location of these regions are fixed among the lepidopteran insects, whereas their sequences are highly diverged even in the two congeneric species examined, such as $O$. furnicalis and $O$. nubilalis, B. mori and B. mandarina (Cameron and Whiting, 2008). Most intergenic spacers include multiple short microsatellite-like repeat regions such as (TA), poly-A and poly-T in P. flavescens.

The 351-bp AT-rich region is within the size range from $319 \mathrm{bp}$ in O. lunifer (Salvato et al., 2008) to 747 bp in B. mandarina (Pan et al., 2008) detected in particular lepidopteran species to date (Table 5). This region was located between the $r r n S$ and $\operatorname{trn} M$ genes as we expected, with the A+T content of $93.2 \%$, which is also well within the range of other lepidopterans from $88.0 \%$ in A. melete (Hong et al., 2009) to $98.5 \%$ in Phthonandria atrilineata (Yang et al., 2009).

Table 5. Comparison of the total non-coding regions of lepidopteran mitochondrial genomes.

\begin{tabular}{|c|c|c|c|}
\hline Species & Total size (bp) & A+T-rich (bp) & Non-D-loop (bp) \\
\hline Artogeia melete & 15,140 & 351 & 14,789 \\
\hline Argyreus hyperbius & 15,156 & 349 & 14,807 \\
\hline Eumenis autonoe & 15,489 & 678 & 14,811 \\
\hline Acraea issoria & 15,245 & 430 & 14,815 \\
\hline Teinopalpus aureus & 15,242 & 419 & 14,823 \\
\hline Papilio maraho & 16,094 & 1270 & 14,824 \\
\hline Sasakia charonda kuriyamaensis & 15,222 & 380 & 14,842 \\
\hline Sasakia charonda & 15,224 & 380 & 14,844 \\
\hline Parnassius bremeri & 15,389 & 504 & 14,885 \\
\hline Spilonota lechriaspis & 15,368 & 441 & 14,927 \\
\hline Eriogyna pyretorum & 15,327 & 357 & 14,969 \\
\hline Coreana raphaelis & 15,360 & 375 & 14,985 \\
\hline Antheraea yamamai & 15,338 & 334 & 15,004 \\
\hline Antheraea pernyi & 15,566 & 552 & 15,014 \\
\hline Helicoverpa armigera & 15,347 & 328 & 15,021 \\
\hline Saturnia boisduvalii & 15,360 & 330 & 15,030 \\
\hline Phthonandria atrilineata & 15,499 & 457 & 15,042 \\
\hline Hyphantria cunea & 15,481 & 357 & 15,124 \\
\hline Lymantria dispar & 15,569 & 435 & 15,134 \\
\hline Bombyx mori & 15,643 & 499 & 15,144 \\
\hline Diatraea saccharalis & 15,490 & 335 & 15,165 \\
\hline Bombyx mandarina & 15,928 & 747 & 15,181 \\
\hline Adoxophyes honmai & 15,680 & 490 & 15,190 \\
\hline Manduca sexta & 15,516 & 324 & 15,192 \\
\hline Ochrogaster lunifer & 15,593 & 319 & 15,274 \\
\hline Phalera flavescens & 15,659 & 351 & 15,308 \\
\hline
\end{tabular}

Twenty-six lepidopteran species in this study arranged from the shortest to the longest in the size of the non- $D$-loop region.

The microsatellite-like (AT) ${ }_{6}$, ACC(AT) ${ }_{6}$ and 16-bp poly-T elements were present in the flanking area of the $P$. flavescens $D$-loop region, and this case is similar to that found in other lepidopterans, such as ATTTA(AT) $)_{7}$ ATTTA(TA) $)_{8}$, ATTTA(AT) $)_{9}$ ATTTA(AT) ${ }_{10}$, ATTTA(AT) $)_{7}(\mathrm{TA})_{3}$, and ATTTA(AT) $)_{11}$ in C. raphaelis, M. sexta, B. mandarina, B. mori, $O$. lunifer, and $A$. melete, respectively (Yukuhiro et al., 2002; Kim et al., 2006; Pan et al., 2008; Cameron and Whiting, 2008; Hu et al., 2010; Liao et al., 2010). The motif poly$\mathrm{T}$ stretch was located upstream of the $\operatorname{rrnS} 5$ '-end and preceded by the oligonucleotide ATAGA, and this structural feature is remarkably conserved in the majority of lepidopteran insects (Figure 5). 


\begin{tabular}{|c|c|c|c|c|}
\hline & mmS & & p region & \\
\hline A. permyi & 5' TTATT-------_-_-----CGTAAATTTTTT-CAd & dATAGA-- & TTTTTTTTTTTTTTTTTT & ATATTAAAT -3 \\
\hline A. yamamai & --CGTAAATTTTTT--CGC & CATAGA-- & TTTTTTTTTTTTTTTTTTT & ATATTAAAA-3, \\
\hline E. pysetorum & 5' AAATTTATTTTTTT---------GTAAATTTTTTT--AC & CATAGA-- & TTTTTTTTTTTTTTTTTTT & ATATTAAAA-3' \\
\hline S. boisduvalii & 5' TTATATAT---------------AAATTTTTTT--AC & CATAGA-- & TTTTTTTTTTTTTTTTTT & ATATTAAAA-3, \\
\hline B. mandarina & 5' ATTTAAT--_-_-_-_-_GT-AATTTTTTTT-AC & CATAGA-- & TTTTTTTTTTTTTTTTTTTTTT & ACATTAAAA-3, \\
\hline Nexta & 5 ' AATAGTTAAATTATATAT- & ATAGAS-- & TTTTTTTTTTTTTTTTTT & ATATTAAAA-3' \\
\hline B. mori & 5' ATTTAAT--_-_-_-_-_-_AATTTTTTTT-AC & CATAGA-- & TTTTTTTTTTTTTTTTTT & ATATTAATT $-3^{\prime}$ \\
\hline atrilineata & 5' ATATTTTATTTACTAA-- & ATAGA-- & TTTTTTTTTTTTTTTTTT & AAAATTAAA-3' \\
\hline 0. Iwifer & 5' AATAATAAATTAACTAA- & ATAGA-- & TTTTTTTTTTTTTTTTTTTT & ATATTAAAA-3' \\
\hline P. flavescens & 5 ' TTATATAACTGTAACT- & ATAGA & TTTTTTTTTTTTTTT & AATTTTAAT-3 \\
\hline H. armigera & ---GTAAATTTTTTTAA- & ATAGA-- & TTTTTTTTTTTTTTTTTTT & ATATTAAAA-3' \\
\hline H. cunea & 5' TTATATATATTATTTCTAAT- & ATAGA-- & TTTTTTTTTTTTTTTTTT & ATATTTAAA-3' \\
\hline L. dispar & 5' TTATAATAATTAAATTAAAT- - & ATAGA -- & TTTTTTTTTTTTTTTT & ATATATTAA-3' \\
\hline S. Iechriaspis & 5' ATAAAAA-------ATTTCTAAT--- & ATAGA-- & TTTTTTTTTTTTTTTTTTT & ATATTAAAA- 3 \\
\hline A. honmai & 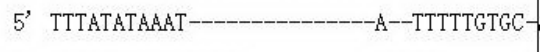 & ATAGATC & TTTTTTTTTTTTTTTTT & ATATTAAAA- 3 \\
\hline 2. saccharalis & 5' ATTTATATTCATATT-- & CATAG-十-- & TTTTTTTTTTTTTTT & ATATTAAAT -3 \\
\hline
\end{tabular}

Figure 5. Sequence alignment of the partial D-loop region of 16 moth species. The boxed nucleotides indicate the conserved motif ATAGA. The replication direction of ATAGA motif + poly-T is indicated by arrow, the same as rrnS.

\section{ACKNOWLEDGMENTS}

Research supported by the Provincial Key Project of the Natural Science Foundation of Anhui Province, China (Grant \#KJ2010A142), the CAS/SAFEA International Partnership Program for Creative Research Teams, Chinese Academy of Sciences (Grant \#KZCX22YW2JC104), and the Opening Funds from the State Key Laboratory of Palaeobiology and Stratigraphy, Nanjing Institute of Geology and Palaeontology, Chinese Academy of Sciences (Grant \#104143).

\section{REFERENCES}

Boore JL (1999). Animal mitochondrial genomes. Nucleic Acids Res. 27: 1767-1780.

Cameron SL and Whiting MF (2008). The complete mitochondrial genome of the tobacco hornworm, Manduca sexta, (Insecta: Lepidoptera: Sphingidae), and an examination of mitochondrial gene variability within butterflies and moths. Gene 408: 112-123.

Cha SY, Yoon HJ, Lee EM, Yoon MH, et al. (2007). The complete nucleotide sequence and gene organization of the mitochondrial genome of the bumblebee, Bombus ignitus (Hymenoptera: Apidae). Gene 392: 206-220.

Coates BS, Sumerford DV, Hellmich RL and Lewis LC (2005). Partial mitochondrial genome sequences of Ostrinia nubilalis and Ostrinia furnicalis. Int. J. Biol. Sci. 1: 13-18.

Feng X, Liu DF, Wang NX, Zhu CD, et al. (2010). The mitochondrial genome of the butterfly Papilio xuthus (Lepidoptera: Papilionidae) and related phylogenetic analyses. Mol. Biol. Rep. 37: 3877-3888.

Gong YJ, Shi BC, Kang ZJ, Zhang F, et al. (2012). The complete mitochondrial genome of the oriental fruit moth Grapholita molesta (Busck) (Lepidoptera: Tortricidae). Mol. Biol. Rep. 39: 2893-2900. 
Hall TA (1999). BioEdit: a user-friendly biological sequence alignment editor and analysis program for Windows 95/98/ NT. Nucleic Acid. Symp. Ser. 41: 95-98.

Hao JS, Li CX, Sun XY and Yang Q (2005). Phylogeny and divergence time estimation of cheilostome bryozoans based on mitochondrial 16S rRNA sequences. Chin. Sci. Bull. 12: 1205-1211.

Hao JS, Su CY, Zhu GP, Chen N, et al. (2007). Mitochondrial 16S rDNA molecular morphology of the main butterflies' lineages and its phylogenetic significance. J. Genet. Mol. Biol. 18: 109-121.

Hong GY, Jiang ST, Yu M, Yang Y, et al. (2009). The complete nucleotide sequence of the mitochondrial genome of the cabbage butterfly, Artogeia melete (Lepidoptera: Pieridae). Acta Biochim. Biophys. Sin. 41: 446-455.

Hong MY, Lee EM, Jo YH, Park HC, et al. (2008). Complete nucleotide sequence and organization of the mitogenome of the silk moth Caligula boisduvalii (Lepidoptera: Saturniidae) and comparison with other lepidopteran insects. Gene 413: 49-57.

Hu J, Zhang DX, Hao JS, Huang DY, et al. (2010). The complete mitochondrial genome of the yellow coaster, Acraea issoria (Lepidoptera: Nymphalidae: Heliconiinae: Acraeini): sequence, gene organization and a unique tRNA translocation event. Mol. Biol. Rep. 37: 3431-3438.

Jiang ST, Hong GY, Yu M, Li N, et al. (2009). Characterization of the complete mitochondrial genome of the giant silkworm moth, Eriogyna pyretorum (Lepidoptera: Saturniidae). Int. J. Biol. Sci. 5: 351-365.

Kim I, Lee EM, Seol KY, Yun EY, et al. (2006). The mitochondrial genome of the Korean hairstreak, Coreana raphaelis (Lepidoptera: Lycaenidae). Insect Mol. Biol. 15: 217-225.

Kim MI, Baek JY, Kim MJ, Jeong HC, et al. (2009). Complete nucleotide sequence and organization of the mitogenome of the red-spotted apollo butterfly, Parnassius bremeri (Lepidoptera: Papilionidae) and comparison with other lepidopteran insects. Mol. Cells 28: 347-363.

Kim SR, Kim MI, Hong MY, Kim KY, et al. (2009). The complete mitogenome sequence of the Japanese oak silkmoth, Antheraea yamamai (Lepidoptera: Saturniidae). Mol. Biol. Rep. 36: 1871-1880.

Kim MJ, Wan X, Kim KG, Hwang JS, et al. (2010). Complete nucleotide sequence and organization of the mitogenome of endangered Eumenis autonoe (Lepidoptera: Nymphalidae). Afr. J. Biotechnol. 9: 735-754.

Kumar S, Tamura K and Nei M (2004). MEGA3: integrated software for molecular evolutionary genetics analysis and sequence alignment. Brief. Bioinform. 5: 150-163.

Lee ES, Shin KS, Kim MS, Park H, et al. (2006). The mitochondrial genome of the smaller tea tortrix Adoxophyes honmai (Lepidoptera: Tortricidae). Gene 373: 52-57.

Li WW, Zhang XY, Fan ZX, Yue BS, et al. (2011). Structural characteristics and phylogenetic analysis of the mitochondrial genome of the sugarcane borer, Diatraea saccharalis (Lepidoptera: Crambidae). DNA Cell Biol. 30: 3-8.

Liao F, Wang L, Wu S, Li YP, et al. (2010). The complete mitochondrial genome of the fall webworm, Hyphantria cunea (Lepidoptera: Arctiidae). Int. J. Biol. Sci. 6: 172-186.

Liu Y, Li Y, Pan M, Dai F, et al. (2008). The complete mitochondrial genome of the Chinese oak silkmoth, Antheraea pernyi (Lepidoptera: Saturniidae). Acta Biochim. Biophys. Sin. 40: 693-703.

Lowe TM and Eddy SR (1997). tRNAscan-SE: a program for improved detection of transfer RNA genes in genomic sequence. Nucleic Acids Res. 25: 955-964.

Nardi F, Carapelli A, Dallai R and Frati F (2003). The mitochondrial genome of the olive fly Bactrocera oleae: two haplotypes from distant geographical locations. Insect Mol. Biol. 12: 605-611.

Niehuis O, Yen SH, Naumann CM and Misof B (2006). Higher phylogeny of zygaenid moths (Insecta: Lepidoptera) inferred from nuclear and mitochondrial sequence data and the evolution of larval cuticular cavities for chemical defence. Mol. Phylogenet. Evol. 39: 812-829.

Ogoh K and Ohmiya Y (2004). Complete mitochondrial DNA sequence of the sea-firefly, Vargula hilgendorfii (Crustacea, Ostracoda) with duplicate control regions. Gene 327: 131-139.

Pan M, Yu Q, Xia Y, Dai F, et al. (2008). Characterization of mitochondrial genome of Chinese wild mulberry silkworm, Bomyx mandarina (Lepidoptera: Bombycidae). Sci. China C Life Sci. 51: 693-701.

Perna NT and Kocher TD (1995). Patterns of nucleotide composition at fourfold degenerate sites of animal mitochondrial genomes. J. Mol. Evol. 41: 353-358.

Qin F, Jiang GF and Zhou SY (2012). Complete mitochondrial genome of the Teinopalpus aureus guangxiensis (Lepidoptera: Papilionidae) and related phylogenetic analyses. Mitochondrial DNA 2: 123-125.

Salvato P, Simonato M, Battisti A and Negrisolo E (2008). The complete mitochondrial genome of the bag-shelter moth Ochrogaster lunifer (Lepidoptera, Notodontidae). BMC Genomics 9: 331.

Simon C, Simon C, Bekenbach A, Crespi B, et al. (1994). Evolution, weighting, and phylogenetic utility of mitochondrial gene sequences and a compilation of conserved polymerase chain reaction primers. Ann. Entomol. Soc. Am. 87 : 651-701.

Thompson JD, Gibson TJ, Plewniak F, Jeanmougin F, et al. (1997). The ClustalX windows interface: flexible strategies for 
multiple sequences alignment aided by quality analysis tools. Nucleic Acids Res. 24: 4876-4882.

Wang XC, Sun XY, Sun QQ, Zhang DX, et al. (2011). Complete mitochondrial genome of the laced fritillary Argyreus hyperbius (Lepidoptera: Nymphalidae). Dongwuxue Yanjiu 32: 465-475.

Wilson K, Cahill V, Ballment E and Benzie J (2000). The complete sequence of the mitochondrial genome of the crustacean Penaeus monodon: are malacostracan crustaceans more closely related to insects than to branchiopods? Mol. Biol. Evol. 17: 863-874.

Yamauchi M, Miya M and Nishida M (2002). Complete mitochondrial DNA sequence of the Japanese spiny lobster, Panulirus japonicus (Crustacea: Decapoda). Gene 295: 89-96.

Yang L, Wei ZJ, Hong GY, Jiang ST, et al. (2009). The complete nucleotide sequence of the mitochondrial genome of Phthonandria atrilineata (Lepidoptera: Geometridae). Mol Biol Rep. 36: 1441-1449.

Yin J, Hong GY, Wang AM, Cao YZ, et al. (2010). Mitochondrial genome of the cotton bollworm Helicoverpa armigera (Lepidoptera: Noctuidae) and comparison with other Lepidopterans. Mitochondrial. DNA 21: 160-169.

Yukuhiro K, Sezutsu H, Itoh M, Shimizu K, et al. (2002). Significant levels of sequence divergence and gene rearrangements have occurred between the mitochondrial genomes of the wild mulberry silkmoth, Bombyx mandarina, and its close relative, the domesticated silkmoth, Bombyx mori. Mol. Biol. Evol. 19: 1385-1389.

Zhang DX and Hewitt GM (1997). Insect mitochondrial control region: a review of its structure, evolution and usefulness in evolutionary studies. Biochem. Syst. Ecol. 25: 99-120.

Zhang DX, Szymura JM and Hewitt GM (1995). Evolution and structural conservation of the control region of insect mitochondrial DNA. J. Mol. Evol. 40: 382-391.

Zhao JL, Zhang YY, Luo AR, Jiang GF, et al. (2011). The complete mitochondrial genome of Spilonota lechriaspis Meyrick (Lepidoptera: Tortricidae). Mol. Biol. Rep. 38: 3757-3764.

Zhu YJ, Zhou GL, Fang R, Ye J, et al. (2010). The complete sequence determination and analysis of Lymantria dispar (Lepidoptera: Lymantriidae) mitochondrial genome. Plant Quarantine 4: 6-11. 